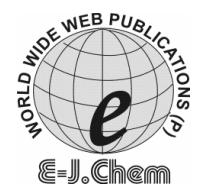

http://www.e-journals.net
ISSN: 0973-4945; CODEN ECJHAO

E-Journal of Chemistry

2009, 6(1), 295-302

\title{
Simultaneous Determination of Rofecoxib and Tizanidine by HPTLC
}

\author{
UTTAM D. PAWAR, ARUNA V. SULEBHAVIKAR ${ }^{\#}$, ABHIJIT V.NAIK, \\ SATISH G. PINGALE and KIRAN V. MANGAONKAR*
}

\author{
Department of Chemistry, \\ Mithibai College of Arts, Chauhan Institute of Science \& \\ Amrutben Jivanlal College of Commerce and Economics, \\ Vile Parle (W), Mumbai -400 056, India. \\ "Department of Chemistry, \\ K. J. Somaiya Senior College of Science and Commerce, \\ Vidyanagar, Vidyavihar, Mumbai-400077, India. \\ uttamar@indiatimes.com
}

Received 14 December 2007; Accepted 10 February 2008

\begin{abstract}
An innovative high performance thin layer chromatography method was developed and validated for simultaneous determination of rofecoxib and tizanidine from tablet dosage form. Rosiglitazone maleate was used as an internal standard. The separation was achieved using HPTLC plates (Merck \#5548) precoated with silica gel $60 \mathrm{~F}_{254}$ on aluminum sheets and a mobile phase comprising of toluene: ethyl acetate: methanol: triethyl amine in volume ratio of 6:3:0.5:0.1 $(\mathrm{v} / \mathrm{v} / \mathrm{v} / \mathrm{v})$, with chamber saturation of $15 \mathrm{~min}$. The plate was developed up to $8 \mathrm{~cm}$ and air dried. The plate was then scanned and quantified at $235 \mathrm{~nm}$. The linearity of rofecoxib and tizanidine were in the range of 3.75 $\mu \mathrm{g} / \mathrm{spot}$ to $11.25 \mu \mathrm{g} / \mathrm{spot}$ and $0.30 \mu \mathrm{g} / \mathrm{spot}$ to $0.90 \mu \mathrm{g} / \mathrm{spot}$ respectively. The limit of detection for rofecoxib and tizanidine was found to be $45.00 \mathrm{ng} / \mathrm{spot}$ and 30.00 $\mathrm{ng} / \mathrm{spot}$ respectively. The limit of quantification for rofecoxib and tizanidine was found to be $135.00 \mathrm{ng} / \mathrm{spot}$ and $90.00 \mathrm{ng} / \mathrm{spot}$ respectively. The percentage assay was found between the range of $99.58 \%$ to $103.21 \%$ for rofecoxib and $98.73 \%$ to $101.55 \%$ for tizanidine respectively, whereas recovery was found between $99.97 \%$ to $100.43 \%$ for rofecoxib and $100.00 \%$ to $101.00 \%$ for tizanidine by standard addition method. The proposed method is accurate, precise and rapid for the simultaneous determination of rofecoxib and tizanidine in dosage form.
\end{abstract}

Keywords: HPTLC, Rofecoxib, Tizanidine, Tablet. 


\section{Introduction}

Pharmaceutical analysis is an integral part of pharmaceutical chemistry. In special drug laboratories the responsibilities of performing analysis is delegated entirely to the staff members. Whenever a new molecule is delivered to have therapeutically beneficial effects; research on the molecule starts as also developing new methods for assay. Today the importance is not only based on the assay of the compound but also on the role played by the analyst in quality control or quality assurance of the product. Thus common research in the pharmaceutical analysis is a continuous process as the synthesis and discovery of a new drug. Not to be outdone one method, which is reported need not spell the end of such an assay. Hence a search is required for a better method where the throughput/unit time is higher and where method is more precise. Rofecoxib ${ }^{1-3}$, described chemically as 4-4'(methyl sulphonyl phenyl)-3-phenyl-5H-furan-2-one is a non-steroidal anti-inflammatory drug. Its molecular formula is $\mathrm{C}_{17} \mathrm{H}_{14} \mathrm{O}_{4} \mathrm{~S}$ and molecular weight is 314.36. Molecular structure of rofecoxib is given Figure 1 (a).

The mechanism of action of rofecoxib is believed to be due to inhibition of prostaglandin synthesis via inhibition of cyclo-oxygenase-2 (COX-2) ${ }^{4}$. Tizanidine hydrochloride $^{1-3}$ is chemically described as 4-chloro- $N$-(4,5-dihydro- $1 H$-imidazol-2-yl)-8thia-7,9 diazabicyclo[4,3,0]nona-2,4,6,9-tetraen-5-amine, centrally acting alpha 2-adregenic drug, widely tested and documented for the treatment of spastic condition associated with muscles. Its molecular formula is $\mathrm{C}_{9} \mathrm{H}_{8} \mathrm{ClN}_{5} \mathrm{~S}$. $\mathrm{HCl}$ and molecular weight is 469.61 . Molecular structure of tizanidine is given Figure1 (b). Its major site of action is in the spinal cord. It preferentially inhibits polysynaptic mechanism responsible for extensive muscle tone, mainly by reducing the excitatory amino acid from interneutrons ${ }^{4}$. Use of rofecoxib and tizanidine in combination is effective against inflammatory pains ${ }^{4}$. Fixed dose containing rofecoxib $(25 \mathrm{mg})$ and tizanidine $(2 \mathrm{mg})$ is available in the market as tablet form. In this present work a new HPTLC method is developed, optimized and validated ${ }^{5-7}$ for the assay of two drugs viz., rofecoxib and tizanidine in combined dosage forms.

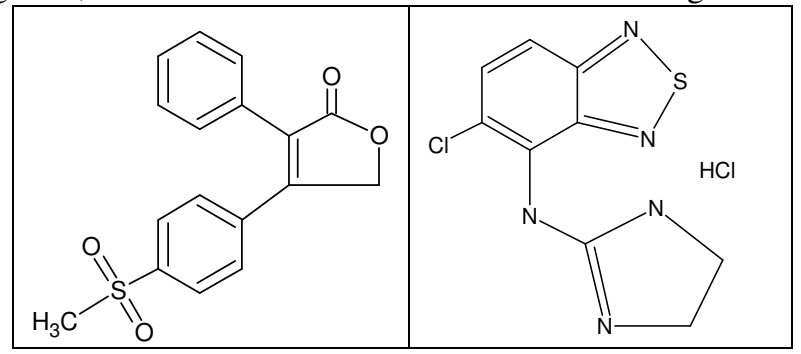

(a) Rofecoxib

(b) Tizanidine

Figure 1. Structure of rofecoxib and tizanidine

In the literature, only one HPTLC ${ }^{8}$ method and few HPLC ${ }^{9-10}$ methods are reported for the simultaneous determination of rofecoxib and tizanidine in dosage form. Although the described HPTLC ${ }^{8}$ method gave reproducible results, however the method was relatively less sensitive (LOD for rofecoxib and tizanidine was found to be $20 \mathrm{ng}$ and $200 \mathrm{ng}$ respectively whereas LOQ was found to be $0.4 \mathrm{mg}$ and $2.0 \mathrm{mg}$ respectively) and it is without internal standard. Along with these, several analytical methods ${ }^{11-21}$ like spectrophotometry, spectroflurimetry and HPLC have been reported for the estimation of rofecoxib and tizanidine from their formulations as well as in biological fluid. In this communication, we 
report a new simple, rapid and sensitive HPTLC method for simultaneous determination of rofecoxib and tizanidine in combination dosage form, which can be used for the routine analysis in ordinary laboratories. Method is developed, optimized and validated accordingly.

\section{Experimental}

\section{Reference standards and chemicals}

The pure reference standards rofecoxib, tizanidine and rosiglitazone were obtained from TDM Labs. Sion, Mumbai as gift reference standard with certificate of analysis. The formulation, tablets sample with combination of rofecoxib $(25 \mathrm{mg})$ and tizanidine $(2 \mathrm{mg})$ is available in market. toluene, acetonitrile, methanol and formic acid used were of analytical grade. All dilutions were performed in standard volumetric flasks.

\section{Preparation of standard stock solutions}

Accurately weighed $251.2 \mathrm{mg}$ of rofecoxib $(99.54 \%)$ was taken in a $25.0 \mathrm{~mL}$ volumetric flask. This was dissolved in minimum quantity of acetonitrile and diluted up to the mark with acetonitrile to get $10,000 \mu \mathrm{g} / \mathrm{mL}$ of rofecoxib (Sol. A).

Accurately weighed $172.4 \mathrm{mg}$ of tizanidine hydrochloride $(98.99 \%)$ was taken in a 25.0 $\mathrm{mL}$ volumetric flask. This was dissolved in minimum quantity of acetonitrile and diluted up to the mark with acetonitrile to get $5,000 \mu \mathrm{g} / \mathrm{mL}$ of tizanidine (Sol. B).

Accurately weighed $167.5 \mathrm{mg}$ of rosiglitazone maleate $(99.19 \%$ ) was taken in a $25.0 \mathrm{~mL}$ volumetric flask. This was dissolved in minimum quantity of acetonitrile and diluted up to the mark with acetonitrile to get $5,000 \mu \mathrm{g} / \mathrm{mL}$ of rosiglitazone maleate (Sol. C).

\section{Preparation of working solution}

Further, the mixture of working solution was prepared by diluting $12.50 \mathrm{~mL}$ of rofecoxib $(10,000 \mu \mathrm{g} / \mathrm{mL})$ and $2.00 \mathrm{~mL}$ of tizanidine $(5000 \mu \mathrm{g} / \mathrm{mL})$ with $0.30 \mathrm{~mL}$ of rosiglitazone, internal standard $(5000 \mu \mathrm{g} / \mathrm{mL})$ stock solution in $50.0 \mathrm{~mL}$ volumetric flask with methanol to get strength of $2500.00 \mu \mathrm{g} / \mathrm{mL}$ of rofecoxib and $200.00 \mu \mathrm{g} / \mathrm{mL}$ of tizanidine.

\section{Preparation of sample solution}

Twenty tablets were (Torroxx-TX ${ }^{\circledR}$ ) weighed and average weight was calculated. These tablets were crushed, powdered and taken in a $10 \mathrm{~mL}$ volumetric flask weight equivalent to one tablet and dissolved in minimum amount acetonitrile. To this flask $0.3 \mathrm{~mL}$ of stock solution of internal standard $(5000 \mu \mathrm{g} / \mathrm{mL}$ of rosiglitazone $)$ was added and diluted up to the mark with methanol and sonicated for $30 \mathrm{~min}$. This solution was then filter through Whatman no. 41.The filtrate was collected in the flask and used as sample solution.

\section{Instrument}

Camag, Linomat IV sample applicator was used. Camag Twin trough glass chamber $(20 \mathrm{x}$ $10 \mathrm{~cm}$ ) was used for development of plates and Camag TLC scanner III equipped with cats 3.0 version software was used for interpretation of data.

\section{Optimized chromatographic conditions}

The experiment was performed on silica gel $60 \mathrm{~F}_{254}$ HPTLC plates pre-coated on aluminum sheet using mobile phase, comprising of toluene: ethyl acetate: methanol: triethyl amine in the volume ratio (6.0:3.0:0.5:0.1). The plate was pre-washed by methanol and activated in an oven at $110^{\circ} \mathrm{C}$ for $1 \mathrm{~h}$ before use. $3.0 \mu \mathrm{L}$ sample solutions were applied on the HPTLC plate as sharp bands of $5 \mathrm{~mm}$ width with the help of Camag Linomat IV sample applicator at 
the distance of $15 \mathrm{~mm}$ from the edge of the HPTLC plate with the speed of $10 \mathrm{sec} / \mu \mathrm{L}$. Ascending development to distance of $8 \mathrm{~cm}$ was performed in saturated $20 \mathrm{~cm} \times 10 \mathrm{~cm}$ camag twin trough chamber for $15 \mathrm{~min}$ at room temperature. The developed TLC plate was air dried and then scanned between 200 and $400 \mathrm{~nm}$ using Camag TLC Scanner III. The wavelength chosen for further quantification was $235 \mathrm{~nm}$. The overlay UV spectra for Rofecoxib and Tizanidine are shown in Figure 2.

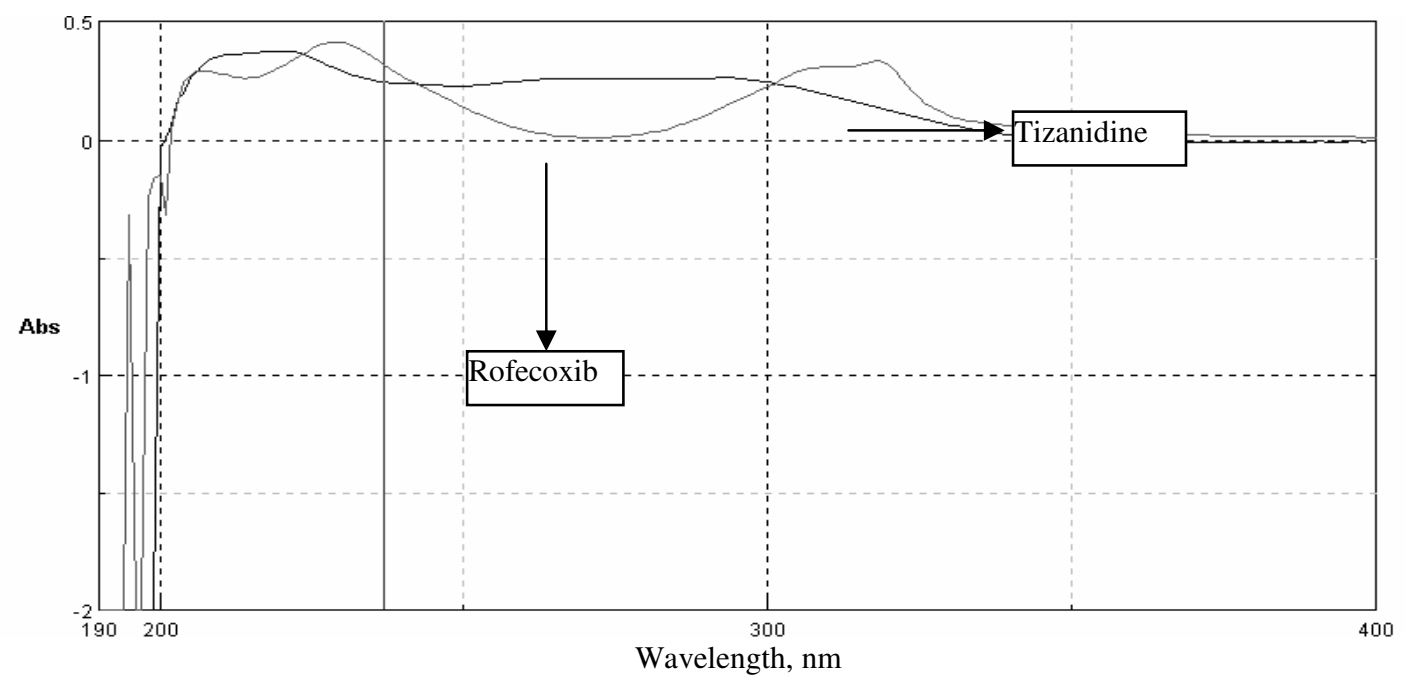

Figure 2. Overlay UV spectra of a) Rofecoxib and b) Tizanidine in methanol

\section{Validation Procedures}

System suitability test

A system-suitability experiment was performed before determination of rofecoxib and tizanidine in unknown samples by spotting $3 \mu \mathrm{L}$ solution of $7.50 \mu \mathrm{g} / \mathrm{spot}$ of Rofecoxib and $0.60 \mu \mathrm{g} / \mathrm{spot}$ of Tizanidine solution. The coefficient of variation (CV) for peak area ratio of value for both the drugs was less than $2.0 \%$ for six replicates measurement of the same sample. This shows that the method and the system both are suitable for determination of rofecoxib and tizanidine.

\section{Linearity}

Validation of the method is a process by which it is established by laboratory studies that the performance characteristics of the method meet the requirements for its intended application. To demonstrate that the proposed method is adequate for its intended use, the method was subjected to statistical validation to determine accuracy and precision. The linearity of a method is a measure of how well a calibration plot of detector response vs. concentration approximates a straight line. Solution containing mixture of rofecoxib and tizanidine of eight different concentrations were prepared in $5.0 \mathrm{~mL}$ volumetric flasks from stock solution in acetonitrile and $0.75 \mathrm{~mL}$ of $1000 \mu \mathrm{g} / \mathrm{mL}$ of Rosiglitazone (internal standard solution) was added to each flask. The concentration range for each of the two pharmaceuticals in the working standard solutions was 1250.00 to $3750.00 \mu \mathrm{g} / \mathrm{mL}$ for Rofecoxib (i. e. 3.75, 4.50, $5.25,6.25,7.50,9.00,10.50$ and $11.25 \mu \mathrm{g} / \mathrm{spot}$ ) and 100.00 to $300.00 \mu \mathrm{g} / \mathrm{mL}$ (i. e. $0.30,0.36$, $0.42,0.54,0.60,0.72,0.84$ and $0.90 \mu \mathrm{g} / \mathrm{spot}$ ) for Tizanidine. To a pre-washed and activated thin layer chromatographic plate, $3 \mu \mathrm{L}$ of the above solutions of different concentrations were applied and the experiment was carried out thrice using instrumentation and 
chromatographic conditions mention above. The plate was then scanned and quantified at 235 $\mathrm{nm}$. The chromatograms were recorded and the peak area ratios (analyte/internal standard) were computed using Camag TLC scanner III equipped with cats 3.0 version software. A typical HPTLC chromatogram is shown in Figure 3. A linear relationship between peak area ratio versus concentration was observed for rofecoxib and tizanidine in the range of 3.75 $\mu \mathrm{g} / \mathrm{spot}$ to $11.25 \mu \mathrm{g} / \mathrm{spot}$ and $0.30 \mu \mathrm{g} / \mathrm{spot}$ to $0.90 \mu \mathrm{g} / \mathrm{spot}$ respectively. This range was selected as linear range for analytical method validation of two components. The data were analyzed by linear regression least-squares fitting. The statistical data obtained are given in Table 1

Table 1. Analytical performance data (Linear regression data for calibration curve)

\begin{tabular}{lcc}
\hline & Rofecoxib & Tizanidine \\
\hline Linear working range (LWR), $\mu \mathrm{g} / \mathrm{spot}$ & $3.75-11.25$ & $0.30-0.90$ \\
Std Err of Y Estimate & 0.9708 & 0.0479 \\
Correlation Coefficient & 0.9976 & 0.9946 \\
X Coefficient(s) & 6.5520 & 2.7256 \\
Constant & -0.2511 & 0.0437 \\
Std Err of Coefficient. & 0.1324 & 0.0817 \\
\hline
\end{tabular}

Assay

$3 \mu \mathrm{L}$ of sample solution was spotted along with same concentration of working solution ( $2500.00 \mu \mathrm{g} / \mathrm{mL}$ of rofecoxib and $200.00 \mu \mathrm{g} / \mathrm{mL}$ of tizanidine) on to the plate under the optimized chromatographic conditions. The procedure was repeated seven times. The peak area ratio values of rofecoxib and tizanidine to the internal standard were calculated. The densitometric responses from the standard and sample were used to calculate the amounts of the drug in the tablet. The results obtained are as shown in Table 2.

Table 2. Results of assay experiment

\begin{tabular}{ccccc}
\hline $\begin{array}{c}\text { Observation } \\
\text { No. }\end{array}$ & $\begin{array}{c}\text { Amount of rofecoxib } \\
\text { found in mg/tablet }\end{array}$ & $\begin{array}{c}\text { Percentage } \\
\text { assay }\end{array}$ & $\begin{array}{c}\text { Amount of tizanidine } \\
\text { found in mg/tablet }\end{array}$ & $\begin{array}{c}\text { Percentage } \\
\text { assay }\end{array}$ \\
\hline 1 & 25.34 & 101.38 & 2.01 & 100.39 \\
2 & 24.90 & 99.62 & 2.00 & 99.92 \\
3 & 25.24 & 100.95 & 1.98 & 98.80 \\
4 & 25.80 & 103.21 & 1.97 & 98.73 \\
5 & 24.90 & 99.58 & 1.99 & 99.45 \\
6 & 25.47 & 101.88 & 1.97 & 98.75 \\
7 & 25.26 & 101.03 & 2.03 & 101.55 \\
Mean & 25.27 & 101.0922 & 1.99 & 99.66 \\
S.D. & 0.3174 & 1.2695 & 0.02 & 1.05 \\
\%CV & 1.26 & 1.26 & 1.06 & 1.06 \\
\hline
\end{tabular}

\section{Limit of detection and limit of quantitation}

The Limit of Detection (LOD) was found to be $45.00 \mathrm{ng} / \mathrm{spot}$ for rofecoxib and 30.00 $\mathrm{ng} / \mathrm{spot}$ for tizanidine. Limit of quantitation (LOQ) for rofecoxib and tizanidine were determined experimentally by spotting six replicates of each drug at LOQ concentration. The LOQ of rofecoxib and tizanidine were found to be $135.00 \mathrm{ng} / \mathrm{spot}$ and $90.00 \mathrm{ng} / \mathrm{spot}$ respectively. The signal to noise ratio is 3 for LOD and 10 for LOQ. 


\section{Recovery studies}

Recovery experiments were carried out to check for the presence of positive or negative interferences from excipients present in the formulation, and to study the accuracy and precision of the method. Recovery experiment was performed by the standard addition method. The recovery of the added standard was studied at three different levels viz $110 \%$, $120 \%$ and $130 \%$ of the estimated amount of the drug. Each set of recovery of added standard was calculated. The results of recovery experiment are tabulated in Table 3.

Table 3. Results from recovery analysis for rofecoxib $(n=7)$

\begin{tabular}{cccccc}
\hline Level & $\begin{array}{c}\text { Amount of rofecoxib } \\
\text { added in, mg }\end{array}$ & $\begin{array}{c}\text { Total amount of } \\
\text { rofecoxib found, mg* }\end{array}$ & SD & $\%$ CV & \%Recovery \\
\hline $0.0 \%$ & $(25.0)+0.00$ & 25.04 & 0.1824 & 0.71 & 100.14 \\
$10 \%$ & $(25.0)+2.50$ & 27.51 & 0.0654 & 0.21 & 100.03 \\
$20 \%$ & $(25.0)+5.00$ & 30.13 & 0.3932 & 1.31 & 100.43 \\
$30 \%$ & $(25.0)+7.50$ & 32.49 & 0.0752 & 0.22 & 99.97 \\
& & & \% Average & 100.14 \\
\hline
\end{tabular}

Table 4. Results from recovery analysis for tizanidine $(n=7)$

\begin{tabular}{cccccc}
\hline Level & $\begin{array}{c}\text { Amount of Tizanidine } \\
\text { added in, mg }\end{array}$ & $\begin{array}{c}\text { Total amount of } \\
\text { Tizanidine found, } \\
\mathrm{mg} *\end{array}$ & SD & \%CV & \%Recovery \\
\hline $0.0 \%$ & $(2.0)+0.00$ & 2.01 & 0.1023 & 0.0021 & 100.50 \\
$10 \%$ & $(2.0)+0.20$ & 2.21 & 0.0264 & 0.0006 & 101.00 \\
$20 \%$ & $(2.0)+0.40$ & 2.42 & 0.0356 & 0.0009 & 101.00 \\
$30 \%$ & $(2.0)+0.60$ & 2.59 & 0.0261 & 0.0007 & 100.00 \\
& & & & \% Average & 100.62 \\
\hline
\end{tabular}

*Each value is average of seven determinations

\section{Results and Discussion}

The method was a normal phase HPTLC method. It makes use of a silica gel $60 \mathrm{~F}_{254}$ stationary phase precoated on aluminium sheet. The mobile phase comprises toluene: ethyl acetate: methanol: triethyl amine in the volume ratio of (6.0:3.0:0.5:0.1) which gives good separation between rosiglitazone maleate (IS) $\left(\mathrm{R}_{\mathrm{f}}=0.27\right)$, tizanidine $\left(\mathrm{R}_{\mathrm{f}}=0.49\right)$ and rofecoxib $\left(\mathrm{R}_{\mathrm{f}}=0.68\right)$. Figure 3 shows a typical densitogram showing well resolution between (1) rosiglitazone (I.S.), (2) tizanidine and (3) rofecoxib. The linearity range for the rofecoxib and tizanidine were found to be 3.75-11.25 $\mu \mathrm{g} / \mathrm{spot}$ and $0.30-0.90 \mu \mathrm{g} / \mathrm{spot}$ respectively. The correlation coefficient was found to be 0.9976 and 0.9946 . That means a good relationship was observed between the concentration ranges of both the drugs. The limit of detection for rofecoxib and tizanidine was found to be $45.00 \mathrm{ng} / \mathrm{spot}$ and $30.0 \mathrm{ng} / \mathrm{spot}$ respectively. The limit of quantification for rofecoxib and tizanidine was found to be $135.00 \mathrm{ng} / \mathrm{spot}$ and 90.00 $\mathrm{ng} / \mathrm{spot}$ respectively. It proves the sensitivity of method for the drugs. The recovery for rofecoxib and tizanidine was found in the range of $99.97-100.43 \%$ and $100.00-101.00 \%$ respectively which indicates that the method is free from interference from excipients present in the formulation. The low values of standard deviation and coefficient of variation at each level of the recovery experiment indicate high precision of the method. 


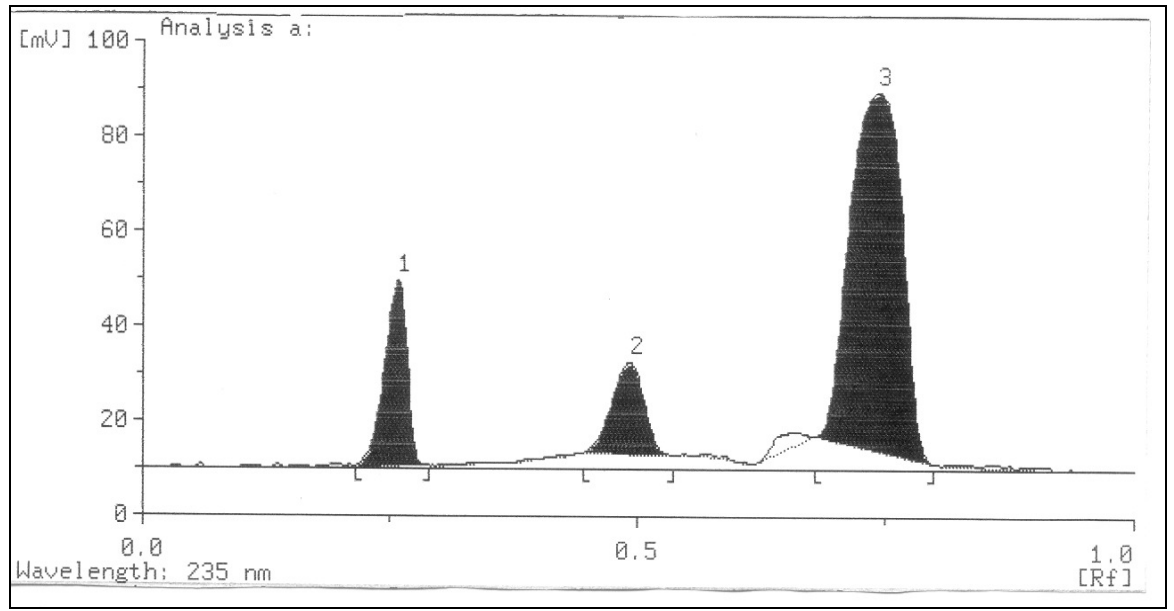

Figure 3. Typical chromatogram Peak, (1) Rosiglitazone maleate (internal standard), (2) Tizanidine and (3) Rofecoxib

\section{Conclusion}

The data given above reveal that the proposed method is simple, accurate and sensitive with good precision and accuracy. This encourages their successful use in routine quality control analysis of rofecoxib and tizanidine from their fixed dosage form as well as raw materials.

\section{Acknowledgements}

The authors thank Ramnarain Ruia College, Matunga Mumbai and TDM Labs. Sion Mumbai for providing gift samples of reference standards of rofecoxib, tizanidine and rosiglitazone. The author's are grateful to Dr. Suhas Pedanekar, Dr. Vikas Vaidya and Dr. Sunita Shailejan for providing facilities to carry out this work and encouragements.

\section{References}

1. George Lunn, HPLC methods for recent approved pharmaceutical analysis, 2003, 2, $562,566,641$.

2. Susan Budavari, Maryadele J O' Neil, Ann Smith, Patricia E Heckelman and Joanne F Kinneary, The Merck Index, $12^{\text {th }}$ Ed., 1996, Merck, USA. (monograph no. 9624) 1618.

3. Susan Budavari, Eds, In, The Merck Index, $13^{\text {th }}$ Ed., Merck \& Co., Inc., Whitestation, NJ, 2001, 1481, 1691.

4. Parfait K, (Ed.) Martindale- The complete Drug reference, $33^{\text {rd }}$ Ed., Pharmaceutical press, 1 Lambeth High Street, London SEI 7 JN, UK, 1993, 768.

5. ICH, Text on validation of analytical procedures, ICH harmonized tripartite guidelines, adapted 27 Oct 1994.

6. Touchstone J C, John Wiley, Practice of thin layer chromatography, Third Edition, Published by and sons, Inc., USA, 1992.

7. Sethi P D, High performance thin layer chromatography Quantitative analysis pharmaceutical formulations, First Edition, CBS Publishers and distributors, India, 1996.

8. Ravi T K, Gandhimathi M, Sireesha K R and Jacob S, Indian J Pharm Sci., 2006, $\mathbf{6 8}(2), 234$. 
9. Subramanian G, Pandey S and Udupa N, Indian J Pharm Sci., 2004, 66 (5), 699.

10. M Gandhimathi, T K Ravi and Susheel John Varghee, Pharm Biomed Anal., 2005, 37(1), 183.

11. Mathew C Z and Halpin R A, Drug Metab Despo., 2002, 28, 1244.

12. Prascit P and Wong Z, Bioorg Med Chem Lett., 2003, 176.

13. Raman B and Pattel D, Indian Drugs., 2002, 30, 63.

14. Billen D, Boens N and Deschryvet F C, J Chem Soc., 2003, 101.

15. Wang H, Handa A K, Suedbalkar V P, Patrick J and Jansen, Int J Pharm., 2001, 45.

16. Woolf E, Ful and Matuzeweski B, J Chromatogr B Biomed Sci Appl., 1999, 730, 221.

17. Chevez-Eng C M, Constanzer M L and Matuzeweski B K, J Chromatogr B Biomed Sci Appl., 2000, 748 (1), 31.

18. Ajithadas Aruna, Anusuya P and Kumar Pavan A R, Indian Drugs, 2001, 38 (10), 523.

19. Bhoir I. C, Raman B and Sundaresan M, Anal Lett., 1998, 31, 1533.

20. Kauffman J M, Lopez R B, Fernandis G M and Patriarch G J, J Pharm Biomed Anal., 1992, 10, 763.

21. Sujata K, Chitra K, Dhanusihka S H, Krishna M V and Janardhan V, Indian Drugs, 2002, 39 (10). 548. 


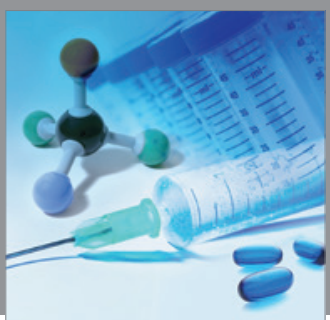

International Journal of

Medicinal Chemistry

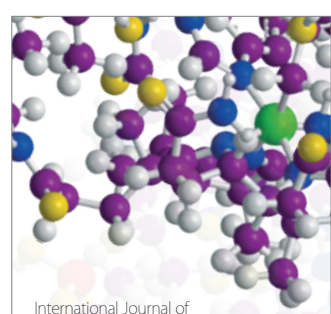

Carbohydrate Chemistry

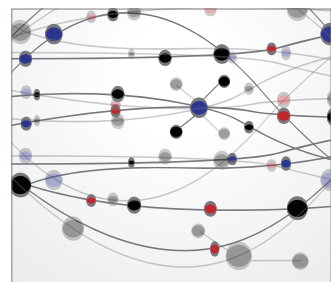

The Scientific World Journal
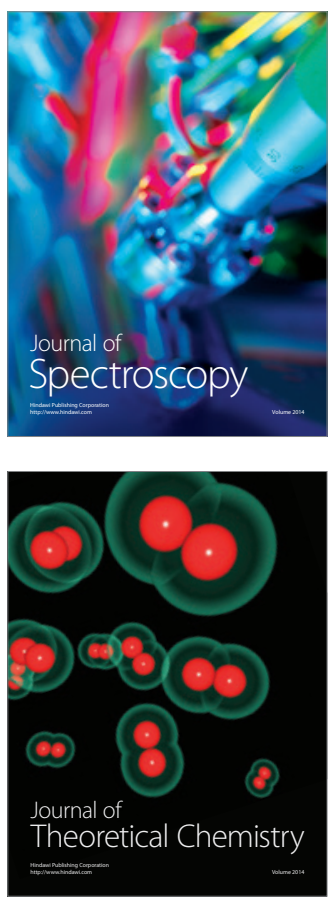
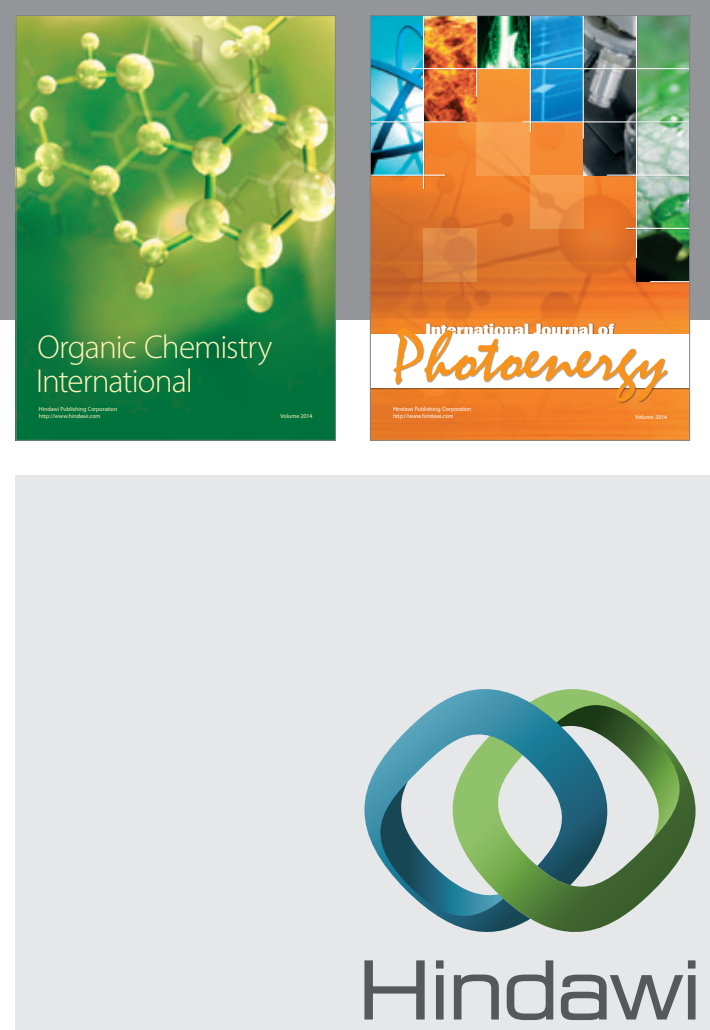

Submit your manuscripts at

http://www.hindawi.com
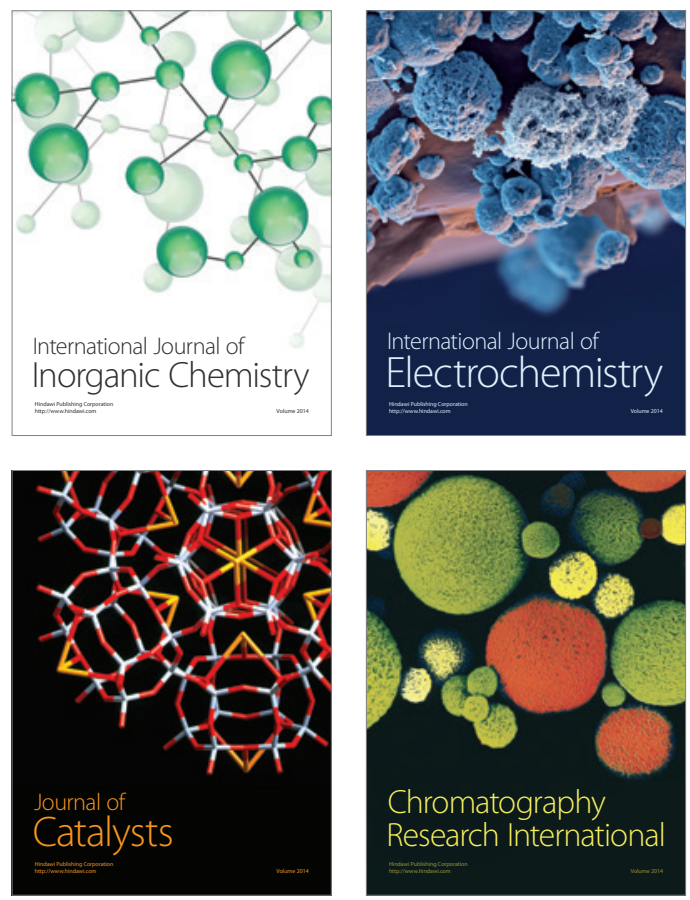
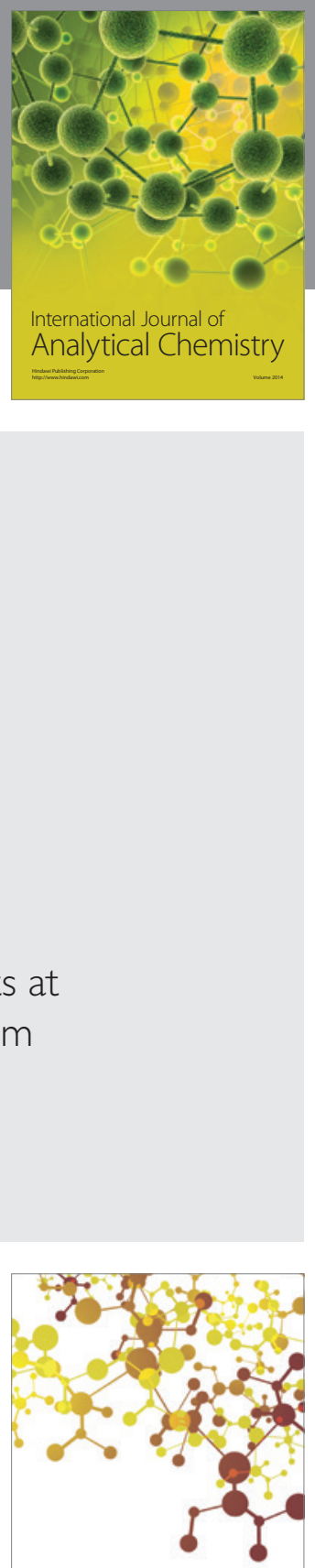

Journal of

Applied Chemistry
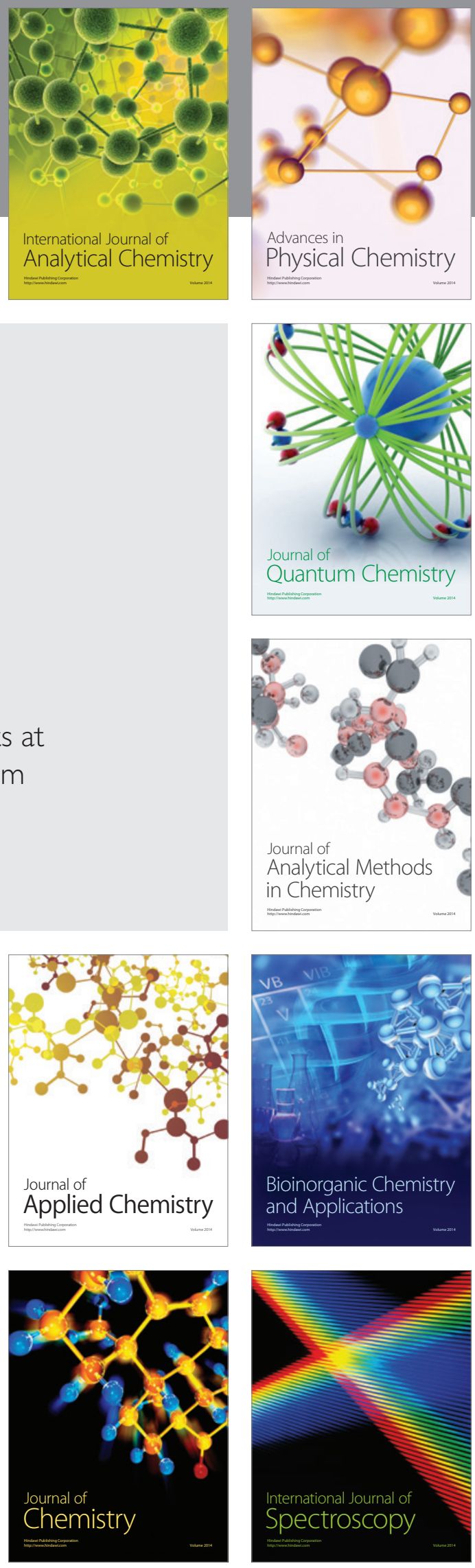